\title{
The problems of calculating the load-bearing structures made of light steel thin-walled profiles
}

\author{
Vera Roy $^{1, *}$, Oxana Izvekova ${ }^{1}$, and Issa Togo ${ }^{1}$ \\ ${ }^{1}$ Peter the Great St. Petersburg Polytechnic University, 29 Politechnicheskaya St., St. Petersburg, \\ 195251, Russia
}

\begin{abstract}
The article presents the results of a study of bearing capacity of thin-walled cold-formed steel beam of the guide profile. Such profiles have a small thickness and complex cross-sectional shape. Bending deformation develops in the cross-sectional plane under the influence of loads in beam. In addition, deformation of constrained torsion and warping arise. These deformations influence the stress distribution at the points of the crosssection of the beam and thereby determine its load-bearing capacity.
\end{abstract}

\section{Introduction}

Today in Russia buildings with load-bearing frame of thin-walled cold-formed sections are widely used [1]. They have a number of technological and operational advantages (lightness, high speed of erection, etc.) [2].

As practice shows, often due to errors in the design of buildings of light steel thinwalled structures (LSTS), frequent cases of emergency [3]. Sustaining the work of such structures is a major problem to the widespread introduction of LSTS in massive construction. Obviously, the thin-walled structures at the design stage requires a thorough analysis of their bearing capacity. Not paying attention to the growing popularity of such structures and a large amount of research on all LSTS stage of development, today in Russia there are significant deficiencies in the prescriptive, methodological and computational databases of design of LSTS which does not make it easy and clear to make their calculation.

Theory of calculation based on the hypothesis of plane sections, are not applicable to the thin-walled bars, due to their small thickness and mismatch the centers of gravity and bending. To solve engineering problems of calculation of elements of thin-walled structures can distinguish two groups of ways to calculate: based on the modeling of shells and rods. The first group of methods is associated with the representation of a thin-walled rod in the form of a shell and further numerical calculation, as a rule, using the finite element method, in the program complexes SCAD, Lira, SOFiSTiK etc. Such methods of calculation are accurate enough, but very time-consuming in the engineering design activities especially in terms of the complex structure analysis. In the second group of methods can be

* Corresponding author: veraroya@gmail.com 
distinguished analytical and numerical methods for calculation of thin rods associated with the introduction of additional "seventh" degree of freedom and the corresponding power factor-bimoment $[2,4,5]$.

Study of the bearing capacity, deformability and manufacturing technology of steel structures of cold-formed sections are devoted to [6-21]. In $[6,11,12]$ are considered the possibility of accounting the seventh degree of freedom in the creation of a thin-walled finite element.

\section{Statement of the research problem}

Let us analyze the degree of influence of component of warping on the stress-strain state of the thin-walled bar.

We will lead the calculation for cantilever balcony beam with cross section GP 254-1.5 [22] like for beam having strain of warping.

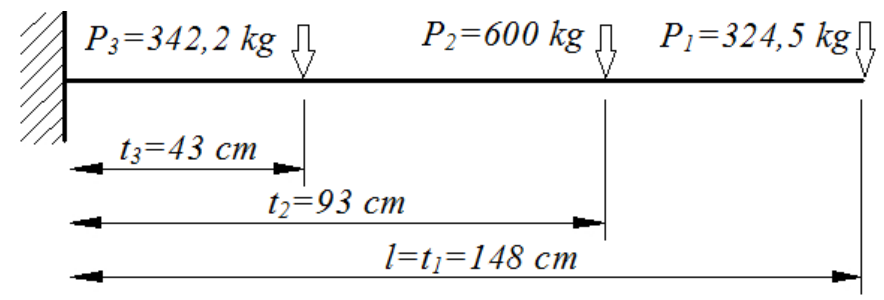

Fig. 1. Design scheme.

\subsection{Calculation of the strength of solid section bent elements}

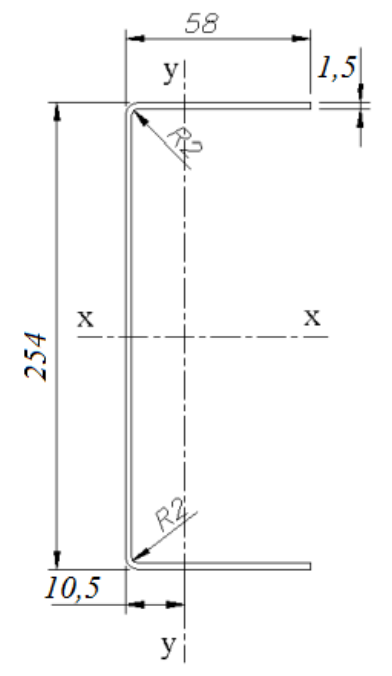

Fig. 2. Cross section [22].

Geometric characteristics in calculation are taken the lower of two: by assortment [22] and by calculation in the program TONUS (PC SCAD Office) - table 1. 
Table 1. Geometric characteristics of cross section GP 254-1.5.

\begin{tabular}{|c|c|c|c|c|}
\hline & Parameter & $\begin{array}{c}\text { Value according to } \\
\text { STO[22] }\end{array}$ & $\begin{array}{c}\text { Value according to } \\
\text { TONUS }\end{array}$ & Units \\
\hline$A$ & Cross sectional area & 5.46 & 5.458 & $\mathrm{~cm}^{2}$ \\
\hline$I_{t}$ & $\begin{array}{l}\text { Moment of inertia at free } \\
\text { torsion }\end{array}$ & - & 0.041 & $\mathrm{~cm}^{4}$ \\
\hline$I_{w}$ & Sectorial moment of inertia & - & 1669.71 & $\mathrm{~cm}^{6}$ \\
\hline$W_{u^{+}}$ & $\begin{array}{l}\text { The maximum moment of } \\
\text { resistance about an axis } U\end{array}$ & 37.99 & 36.8 & $\mathrm{~cm}^{3}$ \\
\hline$W_{v+}$ & $\begin{array}{l}\text { The maximum moment of } \\
\text { resistance about an axis } \mathrm{V}\end{array}$ & 3.28 & 2.973 & $\mathrm{~cm}^{3}$ \\
\hline$I_{u}$ & $\begin{array}{c}\text { The maximum moment of } \\
\text { inertia }\end{array}$ & 484.35 & 466.44 & $\mathrm{~cm}^{4}$ \\
\hline$I_{v}$ & $\begin{array}{l}\text { The mininmum moment of } \\
\text { inertia }\end{array}$ & 16.53 & 14.34 & $\mathrm{~cm}^{4}$ \\
\hline$Y_{b}$ & $\begin{array}{c}\text { Coordinate of the center of the } \\
\text { bend on the } \mathrm{x} \text { axis }\end{array}$ & - & -1.672 & $\mathrm{~cm}$ \\
\hline$Z_{b}$ & $\begin{array}{l}\text { Coordinate of the center of } \\
\text { gravity in the } \mathrm{x} \text { direction }\end{array}$ & 1.05 & 0.906 & $\mathrm{~cm}$ \\
\hline
\end{tabular}

Flexural-torsional characteristics (it is a physical constant of cross section and mathematically representing a characteristic number of differential equation of equilibrium 4th order) [23] amount to:

$$
k=\sqrt{\frac{G J_{t}}{E J_{\omega}}}=0.0030775 \mathrm{~cm}^{-1}
$$

Upon application of a uniformly distributed load and bringing it up to the maximum (destructive) value due to a sufficiently high ductility of the top shelf, which will be significantly deformed, the profile loses its original geometric shape. Load, in most cases being a "stamping" that is more rigid than the section by its nature, will not have tightly fit to the shelf. To indirect accounting for this geometric nonlinearity we will apply the load is not uniform along the shelf, but on the law of the triangle, which is a fairly common method. Then, the resultant load vector will pass through the center of gravity of the load diagram, lying in the intersection of the medians of the triangle, that is, at a distance $(b / 3)$ from the wall edge [4].

As can be seen from Fig. 3 full eccentricity of load application will consist of the eccentricity, due to the mismatch between the center of gravity and the center of the 
bending cross section of $\alpha_{x}$, (equal $\mathrm{Y}_{\mathrm{b}}$ - coordinate of shear center $\mathrm{y}$-axis) and the direct eccentricity of application of the load equal:

$$
e=\alpha_{x}+\frac{b}{3}=1.672+\frac{5.8}{3}=3.605 \mathrm{~cm}
$$

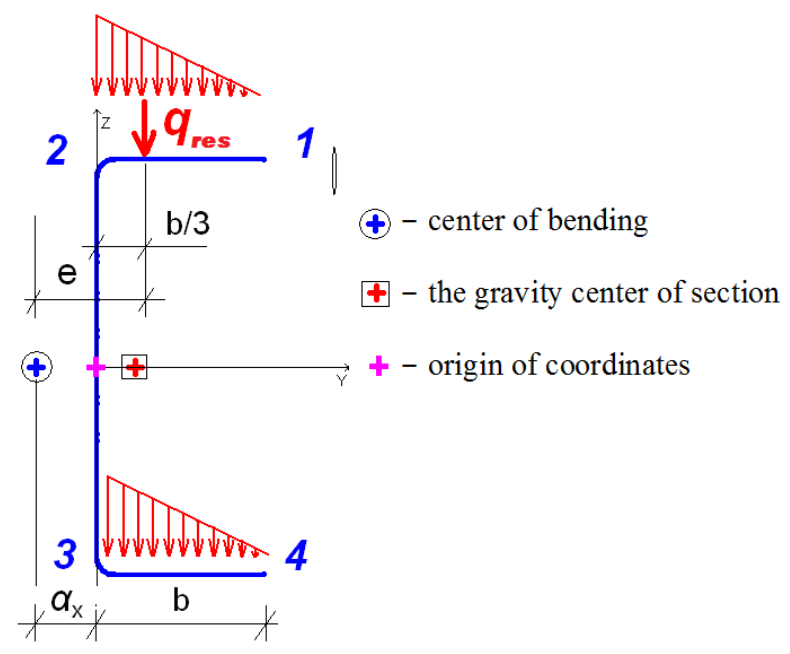

Fig. 3. Scheme of axes and load application, points numbering of $\sigma_{y}$.

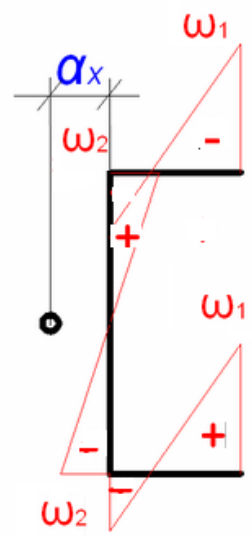

Fig. 4. Diagram of sectoral coordinates [2].

Diagram of sectoral coordinates of section is shown in Fig. 4. The maximum sectoral coordinates are necessary for detecting the stress from bimoment; they comprise:

$$
\begin{gathered}
\omega_{1}=\left(\alpha_{x}-b\right) \frac{h}{2}=(1.672-5.8) \frac{25.34}{2}=-52.30 \mathrm{~cm}^{2} \\
\omega_{2}=\alpha_{x} \frac{h}{2}=21.19 \mathrm{~cm}^{2}
\end{gathered}
$$

According to p. 8.2.1. SR 16.13330-2011[24], calculation of the strength of the beams should be carried out under the action of moments in the two principal planes (and bimoment available) according to the formula 


$$
\frac{M_{x}}{I_{x n} R_{y} \gamma_{c}} y \pm \frac{M_{y}}{I_{x n} R_{y} \gamma_{c}} x \pm \frac{B_{\omega}}{I_{\omega} R_{y} \gamma_{c}} \leq 1
$$

where $\mathrm{x}$ and $\mathrm{y}$ - the distance from the main axis to the point of the section under consideration; while the action in the wall of the beam moment and shear forces.

The bending moment in the reference section:

$$
\begin{gathered}
M=-P_{1} t_{1}-P_{2} t_{2}-P_{3} t_{3} \\
M=-(324.5 \cdot 1.48+600 \cdot 0.93+342.2 \cdot 0.43)= \\
=480.3+558.0+147.4=118540 \mathrm{~kg} \cdot \mathrm{cm}^{2}
\end{gathered}
$$

where $\mathrm{t}-$ the distance from the end of beam to the point of load application, $\mathrm{P}$ - applied load

Assuming that the bending occurs only in one plane, taking $M_{y}=0$

The formula for the bimoment in the case of a cantilever beam, according to the technical literature [2]:

$$
\begin{gathered}
B=-\frac{1}{k} \frac{P e}{c h(k l)}[s h(k(l-t))-s h(k l)] \\
B_{1}=162077.9 \mathrm{~kg} \cdot \mathrm{cm}^{2} \\
B_{2}=191558.4 \mathrm{~kg} \cdot \mathrm{cm}^{2} \\
B_{3}=51702.35 \mathrm{~kg} \cdot \mathrm{cm}^{2}
\end{gathered}
$$

Bimoment in the reference section obtain as a superposition of moments of individual forces:

$$
\begin{gathered}
B=B_{1}+B_{2}+B_{3} \\
B=162077.9+191558.4+51702.35=405339 \mathrm{~kg} \cdot \mathrm{cm}^{2}
\end{gathered}
$$

The maximum normal stress $\sigma_{1}, \sigma_{2}, \sigma_{3}, \sigma_{4}$ occurring in the most tense cross-section, located in the middle of the span, will be different in the four characteristic points $(1,2,3$ and 4, respectively) of the cross-section will be:

$$
\begin{gathered}
\sigma_{1}=\sigma_{x 1}+\sigma_{\omega 1}=-\frac{M_{x}}{W_{x}}+\frac{B_{\omega}}{I_{\omega}} \omega_{1} \\
\sigma_{1}=\frac{118540}{36.8}-\frac{405339}{1669.71} \cdot 52.30=+3221.2-12696.4=-9475.2 \mathrm{~kg} / \mathrm{cm}^{2}
\end{gathered}
$$

Similarly, we calculate the value of the normal stress $\sigma_{2}, \sigma_{3}, \sigma_{4}$ :

Allowable stress:

$$
\begin{aligned}
& \sigma_{2}=-8365.3 \mathrm{~kg} / \mathrm{cm}^{2} \\
& \sigma_{3}=-8365.3 \mathrm{~kg} / \mathrm{cm}^{2} \\
& \sigma_{4}=-9472.2 \mathrm{~kg} / \mathrm{cm}^{2}
\end{aligned}
$$

$$
\sigma_{p e r}=R_{y} \cdot \gamma_{c}=3200 \cdot 0.9=2880 \mathrm{~kg} / \mathrm{cm}^{2}
$$

\subsection{The calculation using the finite element method (analysis of stress-strain state)}

According to p. 8.2.1. SR 16.13330-2011 [24], values of stress in the wall of the beam must be checked according to the following formula in the two principal planes of bending:

$$
\frac{0.87}{R_{y} \gamma_{c}} \sqrt{\sigma_{x}^{2}+\sigma_{y}^{2}-\sigma_{x} \sigma_{y}+3 \tau_{x y}^{2}} \leq 1
$$




$$
\frac{\tau_{x y}}{R_{y} \gamma_{c}} \leq 1
$$

where $\sigma_{x}$ - normal stress in the median plane of the wall, parallel to the longitudinal axis of the beam; $\sigma_{y}$ - same, perpendicular to the longitudinal axis of the beam;

$\tau_{\mathrm{xy}}-$ shear stress in the wall.

$$
\tau_{x y}=\frac{Q \cdot S}{I \cdot t_{w}}
$$

Stress $\sigma_{x}$ and $\sigma_{y}$, taken in formula (20) with their signs and $\tau_{\mathrm{xy}}$, should be determined in the same point of the beam wall.

For this, we use the finite element method in a static statement and solve the problem in

\begin{tabular}{|c|c|c|}
\hline$\nabla$ & $-10672,57$ & .9147 .92 \\
\hline 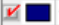 & $-9147,92$ & $.7623,26$ \\
\hline V & $-7623,26$ & $.6098,61$ \\
\hline v $\square$ & $-6098,61$ & -4573.96 \\
\hline$v \square$ & $-4573,96$ & $-3049,31$ \\
\hline$\forall \square$ & $-3049,31$ & $-1524,65$ \\
\hline$x \square$ & $-1524,65$ & 0 \\
\hline$\not \square$ & 0 & 1524,65 \\
\hline$\forall \square$ & 1524,65 & 3049,31 \\
\hline$\forall \square$ & 3049,31 & 4573,96 \\
\hline$\checkmark \square$ & 4573,96 & 6098,61 \\
\hline$x \square$ & 6098,61 & 7623,26 \\
\hline$\forall \square$ & 7623,26 & 9147,92 \\
\hline$\forall ᄃ$ & 9147,92 & 10672,57 \\
\hline
\end{tabular}
the software package SCAD Office.

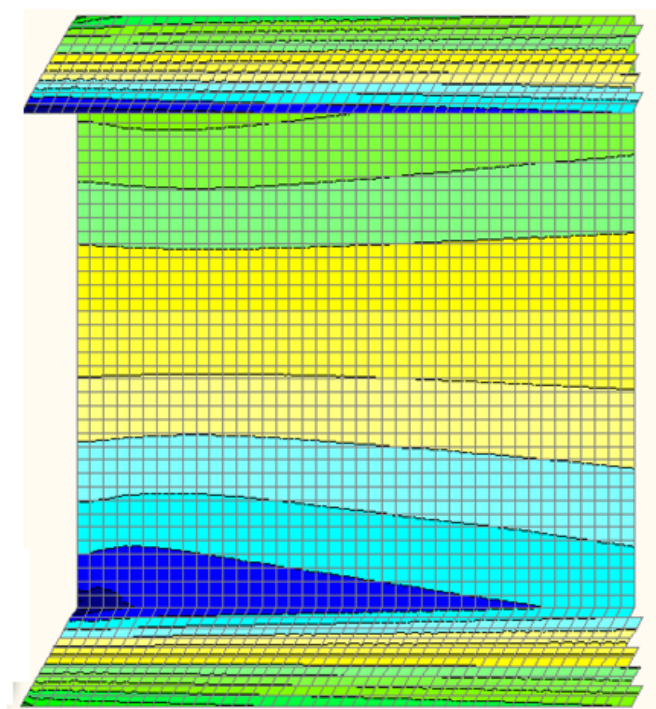

\begin{tabular}{|c|c|c|}
\hline$\sqrt{6}$ & $.3201,77$ & $.2744,37$ \\
\hline 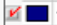 & $.2744,37$ & $.2286,98$ \\
\hline VI & $.2286,98$ & $-1829,58$ \\
\hline$v \square$ & $-1829,58$ & $-1372,19$ \\
\hline$x \square$ & $\cdot 1372,19$ & $.914,79$ \\
\hline 드 & $.914,79$ & $-457,4$ \\
\hline$x \bar{\square}$ & $-457,4$ & 0 \\
\hline$x \square$ & & 457.4 \\
\hline$\checkmark \square$ & 457.4 & 914,79 \\
\hline$\checkmark \square$ & 914,79 & 1372,19 \\
\hline$\checkmark \bar{\square}$ & 1372,19 & 1829,58 \\
\hline$\checkmark \square$ & 1829,59 & 2286,98 \\
\hline$\checkmark \square$ & 2286,98 & 2744,37 \\
\hline$v \square$ & 2744,37 & 3201,77 \\
\hline
\end{tabular}

Fig. 5. Normal stress $\sigma_{\mathrm{y}}$. Minimum value $-10672.57 \mathrm{~kg} / \mathrm{cm}^{2}$, Maximum value $10672.57 \mathrm{~kg} / \mathrm{cm}^{2}$

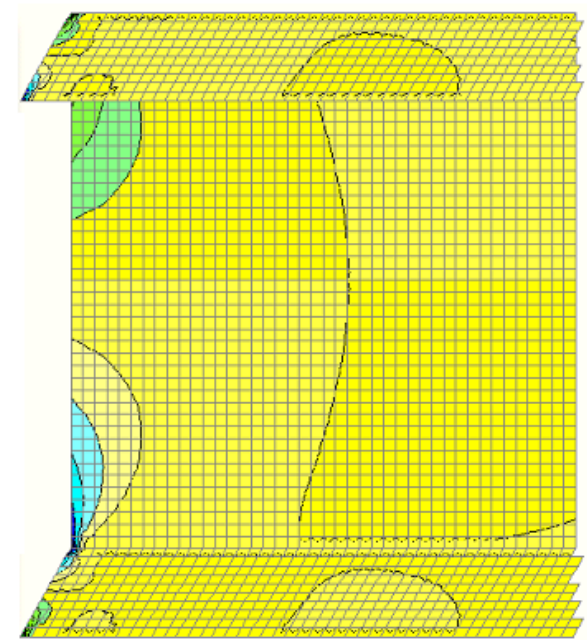

Fig. 6. Normal stress $\sigma_{x}$ Minimum value $-3201.77 \mathrm{~kg} / \mathrm{cm}^{2}$, Maximum value $3201.77 \mathrm{~kg} / \mathrm{cm}^{2}$ 


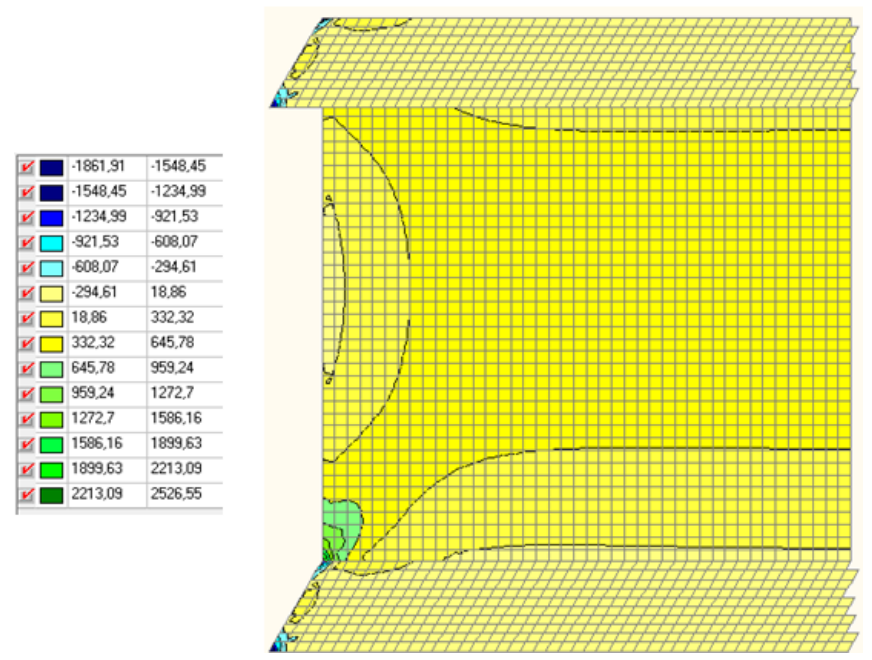

Fig. 7. Shear stress $\tau_{\mathrm{xy}}$. Minimum value $-1861.91 \mathrm{~kg} / \mathrm{cm}^{2}$, Maximum value $2526.55 \mathrm{~kg} / \mathrm{cm}^{2}$

For this, we use the finite element method in a static statement and solve the problem in the software package SCAD Office.

$$
\begin{aligned}
& \frac{0.87}{3200 \cdot 0.9} \sqrt{10672^{2}+3202^{2}-10672 \cdot 3202+3 \cdot 1862^{2}}= \\
& =\frac{0.87}{3200 \cdot 0.9} \cdot 10010=3.02 \mathrm{~kg} / \mathrm{cm}^{2}>1
\end{aligned}
$$

\section{Conclusions}

According to the calculation results, we can conclude that the curvature of the cross section of the thin-walled cold-formed beams significantly affects their stress-strain state. Contribution of bimoment's component is an essential.

In the analysis of the stress-strain state revealed that the strength condition is not met, under a given load the beam of will lose the bearing capacity.

\section{References}

1. N.I. Vatin, A.S. Sinel'nikov, Construction of Unique Buildings and Structures 1, 47-53 (2012)

2. V.A. Rybakov, Osnovy stroitel'noj mehaniki legkih stal'nyh tonkostennyh konstrukcij: ucheb. Posobie (SPbGPU, SPb, 2011)

3. M.R. Garifullin, N.I. Vatin, Construction of Unique Buildings and Structures 6 (21), 32-57 (2014)

4. V.A. Rybakov, O.S Gamayunova, Construction of Unique Buildings and Structures 17, 79-123 (2013)

5. V.A Rybakov, Application of half-moving theory VI Slivkera for analysis of stressstrain state of thin-walled systems (2012)

6. E.L. Ayrumyan, Erecting and Special Works in Construction 3, 2-7 (2008)

7. V.V. Lalin, V.A Rybakov, A. Sergey, Applied Mechanics and Materials 578-579, 858863 (2014)

8. A.I. Alkhimenko, N.I. Vatin, V.A. Rybakov, The light steel constructions techology (SPbGPU, SPb, 2008) 
9. V.A Rybakov, O.S Gamayunova, Stroyyprofil 1, 128-130 (2008)

10. D.A. Trubina, D. Abdulaev, E. Pichugin, V.A. Rybakov, Applied Mechanics and Materials 633-634, 982-990 (2014)

11. D.A. Trubina, D. Abdulaev, E. Pichugin, V.A. Rybakov, Applied Mechanics and Materials 633-634, 1133-1139 (2014)

12. D.A. Trubina, E. Pichugin, V.A. Rybakov, M.R. Garifullin, O. Sokolova, Applied Mechanics and Materials 725-726, 752-757 (2015)

13. V.A. Rybakov, A. Panteleev, G. Sharbabchev, E. Epshtein, Applied Mechanics and Materials 584-586, 1876-1880 (2014)

14. V.A. Rybakov, A. Sergey, Applied Mechanics and Materials 725-726, 746-751 (2015)

15. V.A. Rybakov, N. Molchanova, V. Laptev, A. Suslova, A. Sivokhin, MATEC Web of Conferences 53, 01017 (2016)

16. N.I. Vatin, V.A. Rybakov, Stroyyprofil 2, 60-64 (2007)

17. A.R. Tusnin, O.A. Tusnina, Industrial and Civil Engineering 8, 62-65 (2012)

18. A.O. Gordeeva, N.I Vatin, Engineering and Construction Journal 3 (21), 36-46 (2011)

19. V.V. Lalin, V.A. Rybakov, S.A Morozov, Engineering and Construction Journal 1(27), 53-73 (2012)

20. V.V. Lalin, V.A. Rybakov, Engineering and Construction Journal 8 (26), 69-80 (2011)

21. A.R.Tusnin, O.A. Tusnina, Industrial and Civil Engineering 8, 62-65 (2012)

22. STO 96199376-002-2008 Standard Organization. Steel bent profile, for production of buildings and structures on the LSTC technology (2008)

23. V.Z. Vlasov, Tonkostennye uprugie sterzhni (Strojizdat, Moscow, 1940)

24. SP 16.13330.2011 Steel structures. Updated edition SNIP II-23-81(2011) 